\title{
ЛИНГВОЭКСПЕРТОЛОГИЯ
}

УДК 81'272, ББК 81.5, ГСНТИ 16.31.61, КОД ВАК 10.02.01

T. В. Бердникова

Саратов, Россия

\section{ВЫДВИЖЕНИЕ КАК СРЕДСТВО СОЗДАНИЯ ЭКСПРЕССИВНОСТИ: К ВОПРОСУ ИНТЕРПРЕТАЦИИ ЭКСТРЕМИСТСКИХ ТЕКСТОВ (НА МАТЕРИАЛЕ ПУБЛИКАЦИИ «БЕЛЫЙ БУКВАРЬ»)}

В статье рассматриваются способы создания выдвижения в материалах экстремистской направленности. Исследуется выдвижение как средство создания экспрессивности. Анализу подвергаются такие средства выдвижения, как заголовок, расширенное описание, не традиционное для современной русской орфографии написание слова, адресованность, ассоииативность. В качестве материала выступает публикация, размещенная в сети Интернет, - «Бельй букварь». Рассматриваются особенности «научных» и «учебных» жанров, которые используют авторы материалов экстремистской направленности. В статье выявляется специфика жанра букваря применительно к экстремистским материалам. Анализ проводится с учетом жанра публикации, коммуникативной ситуации, языковых средств выражения выдвижения как средства создания экспрессивности текста.

Ключевые слова: выдвижение, экспрессивность, речевой экстремизм, лингвистическая экспертиза.

Сведения об авторе: Татьяна Владимировна Бердникова, кандидат филологических наук, доиент, заведующая отделом ФБУ Саратовская лаборатория судебной экспертизы Министерства юстицฺии Российской Федераџии. 410028, Саратов, ул. Вольская, 11а, к. 155. E-mail: sintax2@yandex.ru 
T. V. Berdnikova

Saratov, Russia

FOREGROUNDING AS A MEANS OF CREATING EXPRESSIVENESS: ON INTERPRETATION OF THE EXTRIMIST TEXTS (A CASE STUDY OF «WHITE ABC BOOK» PUBLICATION)

The article deals with the methods of creating foregrounding in the materials of extremist slant. Foregrounding as a means of creating expressiveness is studied. The author analyzes such means of foregrounding as title, extended description, non-traditional for modern Russian spelling of a word, addressing character, associativity. The material under study is the publication posted on the Internet - «White ABC-book». The features of «scientific» and «educational» genres used by the authors of extremist materials are considered. The article reveals the specificity of the ABC-book genre related to extremist materials. The analysis is carried out taking into account the genre of publication, communicative situation, and linguistic means of foregrounding as a way of creating expressiveness of the text.

Key words: nomination, expressiveness, speech extremism, linguistic examination.

About the author: Tatyana Vladimirovna Berdnikova, Doctor of Philology, Professor, Head of Division in Saratov Laboratory of Forensic Science of the Ministry of Justice of the Russian Federation. 410028, Saratov, ul.Volskaya 11, k. 155.E-mail: sintax2@yandex.ru

За последние годы материалы экстремистской направленности все чаще становятся объектом лингвистической и психолого-лингвистической экспертизы. Это тексты, интернет-комментарии, печатные периодические и непериодические издания, поликодовые тексты и т.д.

Среди многообразия экстремистских материалов достаточно распространена т.н. «учебная» и «научная» литература, к жанрам которой авторы прибегают для создания большей достоверности и убедительности своей точки зрения. Часто в жанре научной монографии представлены книги, основной темой которых является происхождение наций, рас, религий и т.д. (например, «Расология» В. Авдеева, в которой автором репрезентируется научный подход к исследованию происхождения рас и т.п.).

Особое место среди «учебных» материалов занимает такой жанр, как букварь. Букварь - «азбука, учебник для первоначального обучения грамоте; служит целям воспитания детей, развития их речи и логического мышления. 
Включает материал, формирующий у воспитанников нормы поведения и взаимоотношений между старшими и младшими. Основные структурные звенья букваря - буквы, буквосочетания, слоги, цифры, грамматические сведения, обращения к детям и родителям, наставления, текстовые и иллюстрированные материалы, схемы, таблицы» [Национальная педагогическая энциклопедия: URL]. Основными функциями этого жанра являются обучающая, ознакомительная, воспитательная, поучительная. Поскольку адресатом букваря является младший школьник, он призван не только знакомить ребенка со знаниями, но и воспитывать, наставлять читающего.

Таким образом, создавая текст в жанре букваря, автор имеет следующие цели: обучить, наставить, воспитать читателя.

Одним из таких букварей, поступивших на исследование с целью выявления признаков экстремистских значений, является «Белый букварь». Данный информационный материал, распространенный в сети Интернет на сайте http://talks.guns.ru, был признан экстремистским (решение Октябрьского районного суда г. Ижевска от 01.06.2010) и внесен в Федеральный список экстремистских материалов [Федеральный список экстремистских материалов РФ: URL]. Несмотря на это, «Белый букварь» почти в полном объеме представлен в сети Интернет.

«Белый букварь» содержит рисунки и тексты в стихотворной форме. Тексты снабжены картинками, выполненными в упрощенной, символическисхематичной манере, что соответствует жанру и цели букваря - максимально точно и доступно объяснить понятия. Таким образом, это поликодовый текст, то есть текст, в котором содержатся две знаковые системы (вербальная и визуальная), «смысл которых создается совокупностью различных знаковых систем, например, с помощью слова и изображения, слова и музыки, музыки и танца и пр.» [Судебная лингвистика 2015: 56].

Приведем несколько примеров страниц «Белого букваря»: 


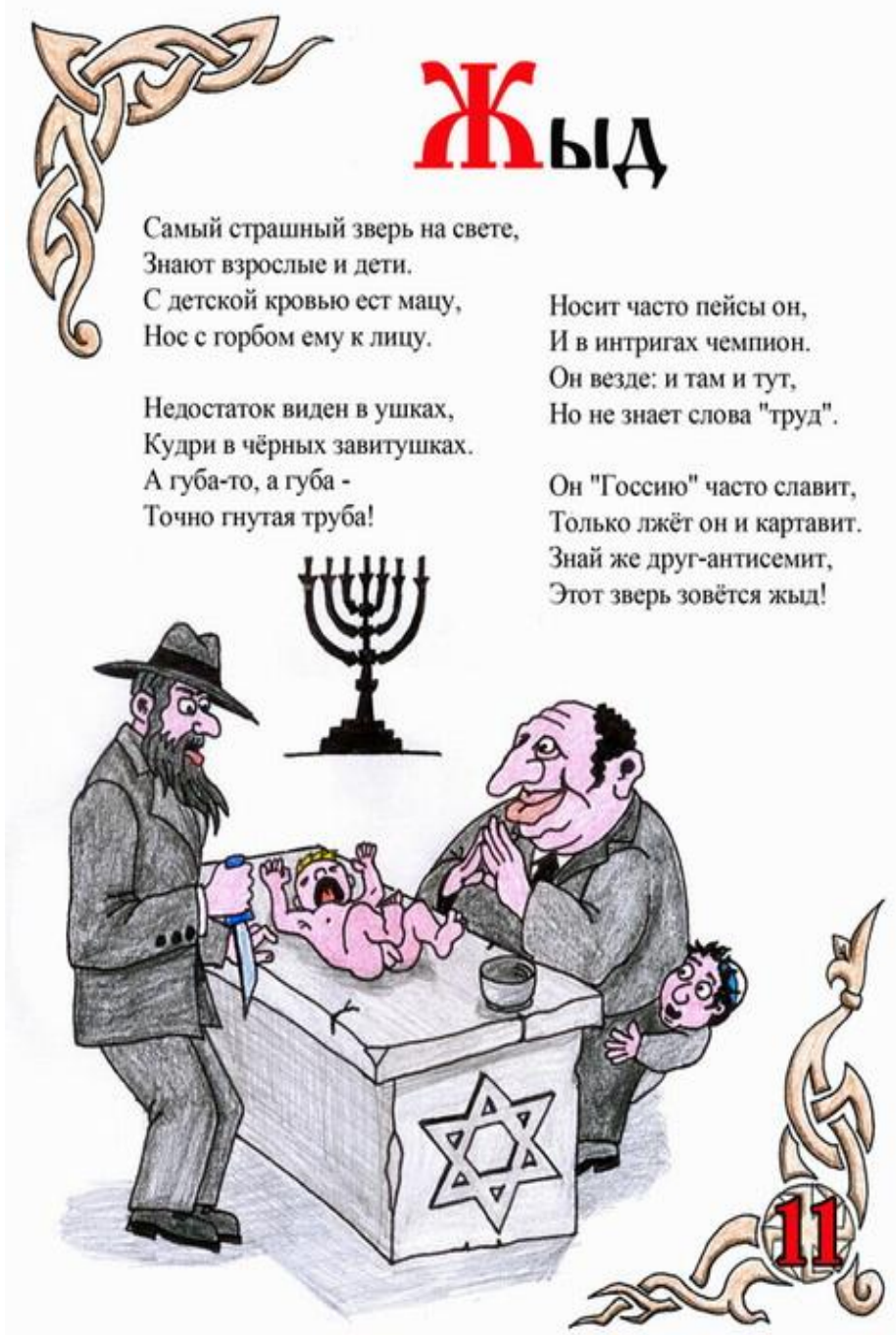

Жйd

Самый страшный зверь на свете,

Знают взрослье и дети.

С детской кровью ест маиу.

Нос с горбом ему клииу.

Недостаток виден в ушках,

Кудри в черных завитушках.

А губа-то, а губа -

Точно гнутая труба!

Носит часто пейсы он,

И в интригах чемпион.

Он везде: и там и тут.

Но не знает слова «труд». 
Он «Госсию» часто славит.

Только лжет он и картавит.

Знай же друг-антисемит,

Этот зверь зовется жыд!

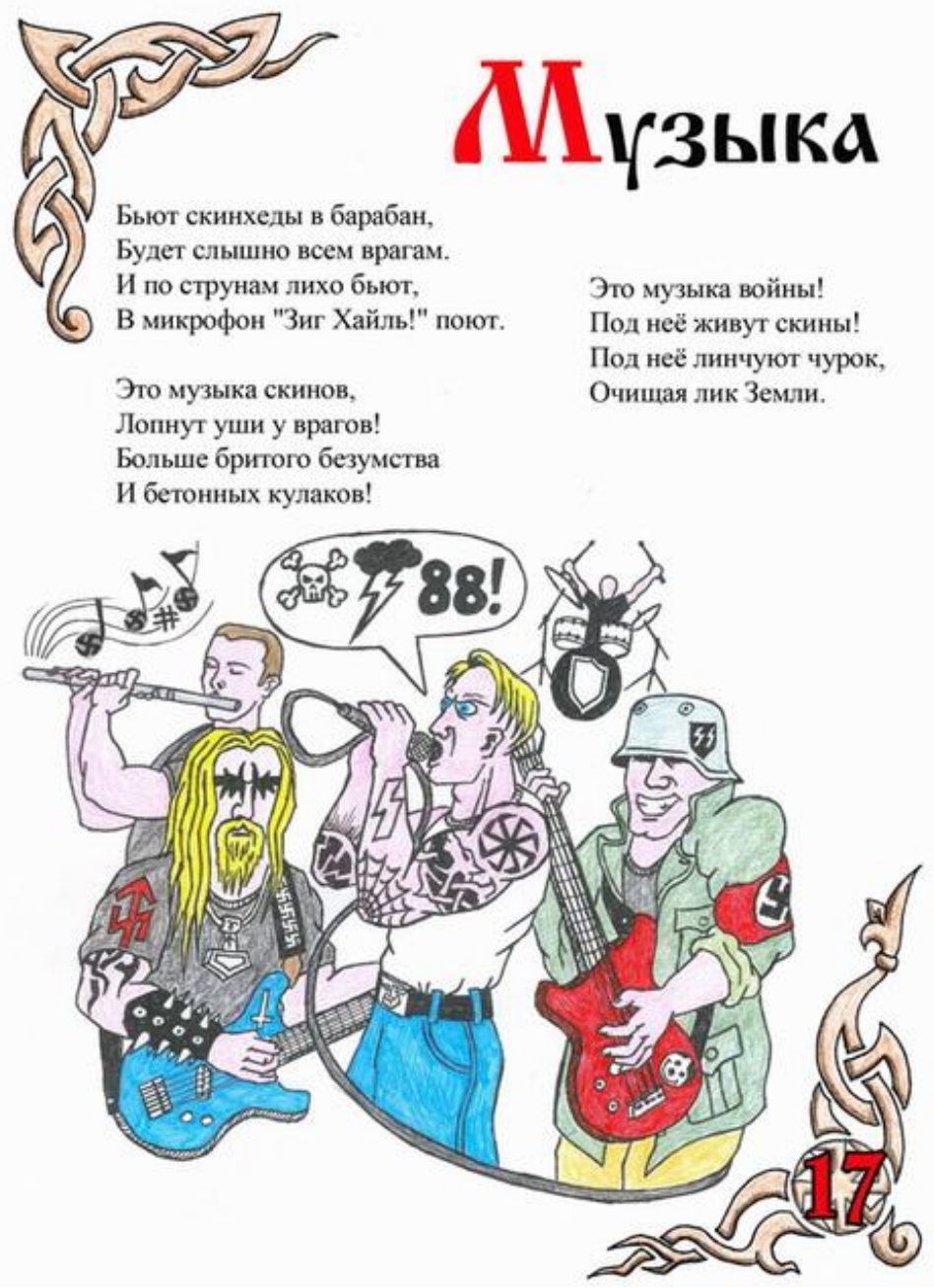

Музыка

Бьют скинхеды в барабан,

Будет сльшно всем врагам.

И по струнам лихо бьют.

В микрофон «Зиг Хайль!» поют.

Это музыка скинов,

Лопнут уши у врагов!

Больше бритого безумства

И бетонных кулаков! 
Это музыка войны!!

Под нее живут скинь!!

Под нее линчуют чурок,

Очищая лик Земли.

Проблема интерпретации при исследовании подобного рода материалов включает в себя ряд вопросов, которые связаны прежде всего с жанром данного объекта.

С одной стороны, в таких текстах (в широком смысле слова) присутствует пародийный компонент.

Согласно определению, данному в Русском семантическом словаре, пародия - художественное произведение, в юмористической или сатирической форме подражающее другому произведению [Русский семантический словарь 2002]. «Белый букварь» подражает учебному букварю для младших школьников: автор намеренно создает образы, которые скорее относятся к понятию «черный юмор». Цель такого букваря - познакомить читателя с националистической, экстремистской идеологией, с важными для автора понятиями.

С другой стороны, имеет место художественная стилизация. «Белый букварь» стилизован под учебный школьный букварь: в нем содержатся статьи, которые представлены как объяснение слов и понятий. Данные статьи иллюстрируются цветными, упрощенными картинками. Поскольку текст имеет стихотворную, образную структуру, следует говорить о его соотнесенности с жанрами художественной речи, в частности, со стихотворением. Таким образом, «Белый букварь» в жанровом плане имеет две составляющих: «учебно-научную» (вернее, псевдонаучную) и художественную. Обе эти стороны необходимо учитывать при анализе подобного рода текстов. Это становится возможным при применении понятия выдвижения.

Вслед за И. В. Арнольд мы понимаем понятие выдвижения как «наличие в тексте каких-либо формальных признаков, фокусирующих внимание читателя на некоторых чертах текста и устанавливающих смысловые связи между элементами разных уровней или дистантными элементами одного уровня» 84 
[Арнольд 2010: 205]. Выдвижение, в отличие от формального переключения внимания читателя, «выполняет целый ряд смысловых функций, одной из которых является повышение экспрессивности» [Арнольд 2010: 206].

Рассмотрим средства выдвижения на примере страницы «Белого букваря» со стихотворением «Жыд».

Во-первых, в качестве средства выдвижения выступает заголовок, то есть информация, представленная в сильной позиции и прогнозирующая читателя на восприятие следующего за заголовком текста, - «жыд».

Слово «жид» имеет значение «презрительное название еврея» [Толковый словарь русского языка 1935; Словарь русского языка 1999; Большой толковый словарь русского языка 1998; Словарь современного русского города 2003; Химик 2004; Большой академический словарь русского языка 2006]. Данная лексема в совокупности с общим контекстом выражает признаки значения «унижение», для которого, согласно «Методике проведения судебной психолого-лингвистической экспертизы материалов по делам, связанным с противодействием экстремизму и терроризму», характерна негативная оценка данной группы, ее представителей, ее ценностей. Выражена речевая цель: информирование об отношении к предмету речи: «я это/так говорю о них (о вас), потому что оцениваю низко, не считаю их (вас) равным себе, своей группе; я этого не скрываю и хочу, чтобы аудитория знала о моем отнотении» [Кукушкина, Сафонова, Секераж 2014].

Текст строится таким образом, что читателю предлагается догадаться, о ком он написан. Для этого используется описание внешности персонажа («жыда»), что является еще одним средством выдвижения: Нос с горбом ему к лииу./ Недостаток виден в ушках,/ Кудри в черных завитушках./ А губа-то, а губа -/ Точно гнутая труба!/ Носит часто пейсы он,/ Только лжет он и картавит. Описание внешних признаков сочетается с описанием внутренних качеств и традиций, характерных для людей еврейской национальности: $C$ детской кровью ест маиу. И в интригах чемпион. Он везде: и там и тут. Но не знает слова «труд». Он «Госсию» часто славит. Только лжет он и картавит. 
Кроме того, в качестве еще одного средства выдвижения можно выделить написание слова через букву «ы», которое является отличным от традиционного для современной русской орфографии написанием. Это свидетельствует о негативно-оценочном отношении автора к людям еврейской национальности, поскольку звук [ы], согласно шкале А.П. Журавлева, относится к «темным» цветам, следовательно, слово «жыд» с подобным написанием может вызывать негативные ассоциации. Ассоциативность также является средством выдвижения.

Еще одним средством выдвижения служит адресованность текста. Под адресованностью понимается направленность текста, ориентация материала на определенную аудиторию, т.н. «фактор адресата» [Арутюнова 1981]. В данном тексте адресат назван как «друг-антисемит»: Знай же друг-антисемит,/ Этот зверь зовется жыд! Однако с учетом коммуникативной ситуации распространение «Белого букваря» в сети Интернет - адресатом может выступать любой пользователь сети Интернет. Таким образом, адресатом становится неопределенный широкий круг лиц, а также эксплицитно обозначенный адресат - «друг-антисемит». Последнего автор стихотворения включает в круг своих единомышленников, потому что для его обозначения используется слово «друг».

Поскольку представленные выше средства выдвижения фокусируют внимание на смысловых акцентах, складывающихся в общую экспрессивноэмоциональную картину, они служат средством создания экспрессивности.

Таким образом, нами были выявлены основные способы выдвижения в текстах экстремистской направленности, к которым относятся:

1) заголовок;

2) расширенное описание;

3) не традиционное для современной русской орфографии написание слова;

4) ассоциативность;

5) адресованность текста. 
В заключение отметим, что при изучении текстов экстремистской направленности следует проводить многоступенчатый анализ, в том числе включающий средства выдвижения.

\section{ЛИТЕРАТУРА}

1. Арнольд И. В. Семантика. Стилистика. Интертекстуальность. М., 2010.

2. Арутюнова Н. Д. Фактор адресата. Известия АН СССР. Серия литературы и языка. 1981. T. 40. № 4. C. 356-367.

3. Большой академический словарь русского языка. СПб., 2006. Т. 5.

4. Большой толковый словарь русского языка. СПб., 1998.

5. Журавлев А. П. Звук и смысл. М., 1991.

6. Кукушкина О. В., Сафонова Ю. А., Секераж Т. Н. Методика проведения судебной психолого-лингвистической экспертизы материалов по делам, связанным с противодействием экстремизму и терроризму. М., 2014.

7. Национальная педагогическая

энциклопедия.

URL: http://didacts.ru/termin/bukvar.html.

8. Русский семантический словарь: толковый словарь, систематизированный по классам слов и значений. М., 2002.

9. Словарь современного русского города. М., 2003.

10. Словарь русского языка: В 4-х тт. М., 1999. Т. 1.

11. Судебная лингвистика. Барнаул, 2015.

12. Толковый словарь русского языка. М., 1935. Т. І.

13. Федеральный список экстремистских материалов. URL: http://minjust.ru/ru/extremist-materials.

14. Химик В. В. Большой словарь русской разговорной экспрессивной лексики. СПб., 2004.

\section{REFERENCES}

1. Arnold I. V. Semantics. Stylistics. Intertextuality [Semantica. Stilistica. Intertekstualnost]. Moscow, 2010.

2. Arutunova N. D. The recipient factor [Factor adresata]. News of Academy of Sciences of the USSR. Series of literature and language. 1981. T. 40. No 4. Pp. 356-367.

3. Large academic dictionary of the Russian language [Bolshoi academicheskiy slovar russkogo yazyka]. T. 5. St.Petersburg, 2006.

4. Large explanatory dictionary of the Russian language [Bolshoi tolkovyi slovar russkogo 
yazyka]. St.Petersburg, 1998.

5. Zhuravlev A. P. Sound and meaning [Zvuk I smysl]. Moscow, 1991.

6. Kukushkina O. V., Safonov Yu. A., Sekera T. N. The methodology of the forensic psycholinguistic examination of cases related to counteraction to extremism and terrorism [Metodika provedeniya psikhologo-lingvisticheskoy ekspertizy materialov po delam, svyzannym s protivodeystviem ekstremismsu I terrarizmu] Moscow, 2014.

7. National pedagogical encyclopedia [Natsionalnaya pedagogicheskaya enciklopediya]. URL: http://didacts.ru/termin/bukvar.html.

8. Russian semantic dictionary: dictionary, classified according to the classes of words and meanings [Russkii semanticheskii slovar: tolkovyi slovar, sistematizirovannyi po klassam slov I znachenii]. Moscow, 2002.

9. Dictionary of modern Russian city [Slovar sovremennogo russkogo goroda]. Moscow, 2003.

10. Dictionary of the Russian language [Slovar russkogo yazyka: 4 t.]. Moscow, 1999. T. 1.

11. Forensic linguistics [Sudebnaya lingvistika]. Barnaul, 2015.

12. Explanatory dictionary of the Russian language [Tolkovyi slovar russkogo yazyka]. Moscow, 1935. T. I.

13. Federal list of extremist materials [Federalnyy spisok ekstremistskih materialov]. URL: http://minjust.ru/ru/extremist-materials.

14. Chimik V. V. Large dictionary of Russian colloquial expressive vocabulary [Bolshoi slovar russkoi razgovornoi ekspressivnoi leksiki]. St.Petersburg, 2004. 